\title{
PUBLIC HEALTH ETHICS: TRADITION, PROFESSION, AND VALUES*
}

\author{
Lawrence O. Gostin**
}

\begin{abstract}
This article asks the difficult questions — what is public health? and what is public health ethics? The article also recognizes that even though public health and biomedical ethics overlap, they have distinct aspects. The article examines the unique population-based perspective of public health and how it can be distinguished from patientcentered biomedical ethics. Additionally, public health scholars and practitioners often use ethical analyses with other forms of reasoning, particularly law and human rights. The article, therefore, explores the relationship among public health ethics, public health law and human rights. The various meanings of each form of reasoning are discussed, as well as the similarities and differences among them. The article concludes with a proposal for reconciling the inherent tradeoffs between public health and civil liberties. Prior to exercising compulsory powers, public health officials should examine the risk to the public; the likelihood that the intervention will be effective; the opportunity costs; the burdens on human rights and the policy's fairness.
\end{abstract}

Key Words: Public health, ethics, public health law, human rights

\section{ÉTICA DE LA SALUD PÚBLICA: TRADICIÓN, PROFESIÓN Y VALORES}

Resumen: Este artículo analiza las difíciles preguntas ¿qué es salud pública? y ¿qué es ética de la salud pública? El artículo también reconoce que aunque la salud pública y la ética biomédica se superponen, abordan distintos aspectos. El artículo examina el enfoque único de la salud pública centrado en la población y cómo éste puede ser distinguido del enfoque de la ética biomédica, centrado en el paciente. Adicionalmente, los teóricos y practicantes de la salud pública frecuentemente utilizan el análisis ético con otras formas de razonamiento, particularmente el legal y el de derechos humanos. Por consiguiente, el artículo discute los diversos significados de cada razonamiento, como también las similitudes y diferencias entre ellos. El artículo concluye con una propuesta para reconciliar las tensiones inherentes entre la salud pública y las libertades individuales. Antes de ejercer poderes compulsorios, los oficiales de salud pública debieran examinar el riesgo para la población; la probabilidad de que la intervención será efectiva; los costos de oportunidad; los costos en términos de derechos humanos y la justicia de la política.

Palabras clave: Salud pública, ética, ley en salud pública, derechos humanos

\section{ÉTICA DA SAÚDE PÚBLICA: TRADIÇÃO, PROFISSÃO E VALORES}

Resumo: Esse artigo analisa as costões difíceis que é saúde pública? e que é ética da saúde pública? O artigo também reconhece que ainda que a saúde pública e a ética biomédica sobrepõem-se, eles abordam diferentes aspectos. O artigo examina o único enfoque à saúde pública centrada na população e como isto pode distinguir do enfoque ao ético biomédico, centrou no paciente. Além disso, os teóricos e profissionais da saúde pública utilizam com freqüência a análise ética com outras formas de raciocínio, em particular o legal e o dos direitos humanos. Em conseqüência, o artigo trata os diversos significados de cada raciocínio , assim como as de semelhanças e de diferenças entre eles. O artigo finaliza com uma proposta para conciliar as tensões inerentes entre a saúde pública e as liberdades individuais. Antes de exercer poderes obrigatórios, os funcionários de saúde pública devem examinar o risco para a população; a probabilidade de que a intervenção será eficaz; os custos de oportunidade; os custos em termos dos direitos humanos e a justiça da política.

Palavras chave: Saúde pública, ética, lei em saúde pública, direitos humanos

* This article is based on a project on public health ethics prepared for the Association of Schools of Public Health.

** J.D., LL.D (Hon.) Professor of Law, Georgetown University. Professor of Public Health, the Johns Hopkins University. Director, Center for Law and the Public's Health.

Correspondence: gostin@law.georgetown.edu 


\section{What Is Public Health?}

In thinking about the application of ethical thought to problems in public health, it is important first to understand what we mean by public health. How is the field defined and what is its content-mission, functions, and services? $(1,2)$. In truth, finding answers to these fundamental questions is not easy because the field of public health is highly eclectic and conflicted $(3,4)$.

Definitions of public health vary widely, ranging from the World Health Organization's(5)utopian conception of health as a "state of complete physical, mental, and social well-being" to a more concrete listing of public health practices. The definition offered by WHO is intended to convey the importance of health, which is more than the absence of illness or disease. Charles-Edward A. Winslow(6, p.30), on the other hand, offers a concrete listing of public health practices. He defines public health as "the science and the art of preventing disease, prolonging life, and promoting physical health and efficiency through organized community efforts for the sanitation of the environment, the control of community infections, the education of the individual in principles of personal hygiene, [and] the organization of medical and nursing service for the early diagnosis and preventive treatment of disease.”

The Institute of Medicine (IOM)(7, p.19), in its seminal report The Future of Public Health, proposed one of the most influential contemporary definitions: "Public health is what we, as a society, do collectively to assure the conditions for people to be healthy." The IOM's definition can be appreciated by examining its constituent parts. The emphasis on cooperative and mutually shared obligation ("we, as a society") reinforces that collective entities (e.g., governments and communities) take responsibility for healthy populations. Individuals can do a great deal to safeguard their health, particularly if they have the economic means to do so. They can purchase housing, clothing, food, and medical care(8). Each person can also behave in ways that promote health and safety by eating healthy foods, exercising, using safety equipment (e.g., seatbelts, motorcycle helmets, or smoke detectors), and by refraining from smoking, using illicit drugs, or drinking alcoholic beverages excessively. Yet there is a great deal that individuals cannot do to secure their health, and therefore these individuals need to organize, build together, and share resources. Acting alone, people cannot achieve environmental protection, hygiene and sanitation, clean air and surface water, uncontaminated food and drinking water, safe roads and products, and control of infectious disease. Each of these collective goods, and many more, are achievable only through organized and sustained community activities(9).

Even the most organized and socially conscious society cannot guarantee complete physical and mental well-being. There will always be a certain amount of injury and disease in the population that is beyond the reach of individuals or government. The role of public health, therefore, is to "assure the conditions for people to be healthy." These conditions include a variety of educational, economic, social, and environmental factors that are necessary for good health.

Most definitions share the premise that the subject of public health is the health of populations -rather than the health of individuals- and that this goal is reached by a generally high level of health throughout society, rather than the best possible health for a few(10). The field of public health is concerned with health promotion and disease prevention throughout society. Consequently, public health is interested in de- 
vising broad strategies to prevent or ameliorate injury and disease.

The traditional role of public health agencies is to identify risks or harms and intervene to prevent or reduce them. Discrete public health powers include testing, reporting, vaccination, treatment, partner notification, and quarantine. Public health authorities, however, are broadening their horizons. They are now interested in the equitable distribution of social and economic resources because social status, race, and wealth are important influences on the health of populations $(11,12)$. Similarly, the field is interested in "social capital" because social networks of family and friends, as well as associations with religious and civic organizations, are important factors in public health $(13,14)$. This inclusive direction for public health is gaining popularity; many governments seek reductions in health disparities and improved social cohesiveness.

The determinants of health include the physical environment, behavior, biology, and social environment. Using this vision, public health researchers and practitioners have ventured into areas of general social policy, ranging from city planning and safe housing $(15,16)$ to violence, war and discrimination(17). The expansive view of public health may well be justified by the importance of culture, poverty, and powerlessness on the health of populations. Social epidemiologists have found an association between these factors and increased morbidity and mortality(18). As a group of prominent ethicists put it, "Justice is Good for Our Health"(19) because fair and compassionate societies tend to produce better health outcomes among their citizens.

\section{What are Public Health Ethics?}

If public health is what society does collectively to assure the conditions for healthy people, then what are public health ethics? Public health ethics may be defined as follows:

The principles and values that help guide actions among public health system actors, which are designed to promote health and prevent injury and disease in the population. The principal values of public health ethics include the salience of population health, safety, and welfare; fairness and equity in the distribution of services; and respect for the human rights of individuals and groups.

In thinking about this definition, it will be helpful to distinguish public health ethics from biomedical ethics. The field of biomedical ethics has richly informed practice and policy in medicine and health care. Biomedical ethics has often stressed the importance of individual interests of patients, notably the right to autonomy, privacy and liberty(20). Ethicists, however, at least until recently, have given insufficient attention to the equally strong values of partnership, citizenship and community(21). As members of a society in which we all share a common bond, we also have an obligation to protect and defend the community against threats to health, safety and security. There remains much work to do in public health ethics. Is the population-based perspective of public health different from the patient-centered perspective of medicine? Is a public health ethic merely the aggregation of individual interests in a population? What is the moral standing that should be attached to the common good? Under what circumstances should individual interests yield to achieve a collective benefit for the population?

Some scholars have thought about public health ethics in three overlapping ways(22): professional ethics (the values that help public health professionals to act in virtuous ways); applied ethics (the values that help to illuminate hard problems in public health policy and 
practice); and advocacy ethics (the overarching value of population health and social justice).

Professional ethics are concerned with the ethical dimensions of professionalism and the moral trust that society bestows on public health professionals to act for the common welfare. This form of ethical discourse stresses the distinct history and traditions of the profession, seeking to create a culture of professionalism among public health students and practitioners. It instills in professionals a sense of public duty and trust. Professional ethics are role oriented, helping practitioners to act in virtuous ways as they undertake their functions. The Public Health Leadership Society in the United States, for example, has developed a Code of Public Health Ethics(23). The Code's principles include the mandate for public health professionals to achieve the fundamental causes of disease; respect individual rights with respect for all cultures; encourage input from community members; empower disenfranchised people; enhance the physical and social environment; protect confidentiality; and assure professional competency. Many believe that a code of ethics, or at least a well-articulated values statement, could increase the status of the field and help clarify the distinctive ethical dilemmas faced by public health professionals. It is true that no single public health profession exists, but rather a variety of different disciplines -e.g., epidemiologists, nurses, sanitary engineers, and public health educators. Still, it is important to find a set of values that is relevant to all those engaging in population-based health.

Applied public health ethics are concerned not so much with the character of professionals as with the ethical dimensions of the public health enterprise itself. Here, scholars study the philosophical knowledge and analytic reasoning necessary for careful thinking and decision making in creating and implementing public health policy. This kind of applied ethics is situation or case-oriented, seeking to understand morally appropriate decisions in concrete cases. Scholars can helpfully apply general ethical theory and detached analytical reasoning to the societal debates common in public health. Applied public health ethics draws from the traditions of utilitarianism, which dictates that benefits are maximized and burdens minimized. Consequently, public health ethics stress the central importance of population health and safety as an overarching value. However, it will also be important to appropriately weigh individual rights in the calculation. The public health model should not assume that the appropriate mode of evaluating options is some form of inflexible cost-benefit test that appears to permit, or even require, that the most fundamental interests of individuals be sacrificed in order to produce the best overall outcome.

In addition to "professional" and "applied" ethics, it is possible to think of an "advocacy" ethic informed by the single overriding value of a healthy community. Under this rationale, public health authorities think they know what is ethically appropriate, and their function is to advocate for that social goal. This populist ethics serves the interests of populations, particularly the powerless and oppressed, and its methods are principally pragmatic and political. Public health professionals strive to convince the public and its representative political bodies that healthy populations, reduced inequalities, and social justice are the preferred societal responses. This argument is supported by a body of literature demonstrating a relationship between socio-economic status and healthy populations.

Public health ethics, therefore, can illuminate the field of public health in several ways. Ethics can offer guidance on (1) the meaning of public health professionalism and the ethi- 
cal practice of the profession, (2) the moral weight and value of the community's health and well-being, (3) the recurring themes of the field and the dilemmas faced in everyday public health practice, and (4) the role of advocacy to achieve the goal of safer and healthier populations.

There needs to be a much more sustained, sophisticated discussion of ethics among students, practitioners and scholars in public health(24). For example, ethics instruction in schools of public health is scarce and targeted primarily to biomedical ethics(25). Further, few public health employers in the public and private sectors offer continuing education that includes ethical issues. Government and academic institutions should consider the value of including ethics in accreditation of schools, credentialing of professionals, and the promotion of public health research.

\section{What is Public Health Law?}

Public health law differs from ethics in that it is concerned with a body of rules of action prescribed by controlling authority and having binding legal force. Law is found in constitutions, which empower governments to act and set limits on their power; statutes, which are enacted by legislative bodies and control the actions of individuals and businesses; regulations, which have similar effects as statutes but are usually promulgated by the executive branch; and court cases, which interpret the constitution, statutes and regulations, often setting binding precedent $(9,26)$.

Law is a primary means with which government creates the conditions for people to lead healthier and safer lives. Law creates a mission for public health authorities, assigns their functions, and specifies the manner in which they may exercise their authority. Law is a tool in public health work which is used to influence norms for healthy behavior, identify and respond to health threats, and set and enforce health and safety standards. The most important social debates about public health take place in legal fora -legislatures, courts, and administrative agencies-and in the law's language of rights, duties and justice.

Public health power is the natural authority of sovereign governments to regulate private interests for the public good. The state possesses a power and a duty to protect, preserve and promote the health, safety, morals, and general welfare of the people. To achieve these communal benefits, the state retains the power to restrict, within constitutional limits, private interests. For example, surveillance or data collection affects privacy; compulsory vaccination or treatment affects bodily integrity; and isolation or quarantine affects liberty. Similarly, public health powers can affect economic interests such as the freedom of contract and the use of property (e.g., licensing and inspection requirements).

Law can be an effective tool to achieve the goal of improved health for the population. Statutes, regulations, and litigation, like other public health prevention strategies, intervene at a variety of levels, each designed to secure safer and healthier populations. First, government interventions are aimed at individual behavior through education (e.g., health communication campaigns), incentives (e.g., taxing and spending powers), or deterrence (e.g., civil and criminal penalties for risky behaviors). The WHO Framework Tobacco Convention, for example, urges countries to adopt laws to reduce tobacco use(27). These include health information designed to inform people about the hazards of smoking; regulation of tobacco advertising and promotions targeted to children, women, or minorities; higher taxes to discourage cigarette purchases; and restraints on export of tobacco products. 
Second, law regulates the agents of behavioral change by requiring safer product design through regulation and tort litigation. The law has done a great deal to make products safer for public use. Governments regulate directly by requiring safety standards for manufacturing. For example, regulations often specify that automobiles have seatbelts and passive restraints and children's toys are safe. The law also allows for indirect regulation through the tort system. For example, individuals may sue manufacturers of inherently dangerous products such as cigarettes and firearms. Both these forms of regulation - direct regulation and tort litigation- have improved design in consumer products.

Finally, law alters the physical (e.g., city planning and housing codes), natural (e.g., clean air and water), and business (e.g., inspections and licenses) environments. The environment in which people live is critical to their health. Government can help make the physical, or built, environment more healthful by controlling toxic exposures such as lead paint, radon, and pests(28). The state can plan cities to encourage exercise (e.g., development of green spaces) and good nutrition (e.g., making available fresh meat and vegetables rather than fast foods). Government can similarly make the natural environment more healthful by regulating air and water quality. The air we breathe, the water we drink, and the pollutants emitted into the environment are powerfully associated with healthy, or unhealthy, living conditions. Finally, government can make the business environment more healthful by requiring safer places to work at and safer corporate practices. Businesses expose their workers to a range of hazards and working conditions. They also have major health impacts on their surrounding communities. It is therefore critically important that the business community takes seriously its obligations toward workers and the neighborhoods in which they operate(14).

\section{What is the Role of Human Rights in Public Health?}

In recent years, human rights have profoundly influenced the field of public health. Historians may reasonably inquire why a body of international law dating back to the midtwentieth century would suddenly become part of the public health discourse. The emphasis on individual rights and liberties that became fashionable in the AIDS pandemic later in the century provides a partial explanation. Civil libertarians turned to the language of human rights to defend persons living with HIV/AIDS from stigma and discrimination(29).

Scholars and practitioners came to see human rights as essential tools in the work of public health. They reasoned that persons who fear government coercion or private discrimination would not come forward for testing, treatment, and partner notification. Individuals who lacked social status and economic power, moreover, would be more vulnerable to infection. Women, for example, may understand that unprotected sex or needle sharing transmits HIV infection, and they may even have the means of protection available (e.g., condoms and sterile injection equipment). But if these women remain powerless in abusive relationships or economically dependent on their partners, they cannot resist unwanted sex or needle sharing, which places them at risk.

The interface between human rights and public health can be described by the following three relationships(30). First, public health policies can violate human rights. The use of compulsory public health powers can interfere with autonomy, bodily integrity, privacy, and liberty. Second, human rights violations can harm public health. The use of torture or inhuman and degrading conditions can harm individuals and populations. Third, policies promoting both human rights and public health result 
in positive, mutually reinforcing outcomes for persons and for society. There often exists a synergistic relationship between health and human rights, so that one supports the other.

The language of human rights is used in different, but overlapping, ways. Some use human rights language to mean a set of entitlements under international law, while others use human rights for its aspirational, or rhetorical, qualities. Depending on the way in which human rights are used, the field can have features that are quite similar to law or ethics.

Legal scholars use human rights to refer to a body of international law that originated in response to the egregious affronts to peace and human dignity committed during World War II. The main source of human rights law within the United Nations system is the International Bill of Human Rights comprising the United Nations Charter, the Universal Declaration of Human Rights, and two International Covenants of Human Rights. Human rights are also protected under regional systems, including those in American, European, and African countries. In Latin America, for example, the PanAmerican Health Organization protects and promotes the health of Latin Americans using several tools, including the OAS Declaration of the Rights and Duties of Man and the Additional Protocol on Human Rights in the Area of Economic, Social, and Cultural Rights, or Protocol of San Salvador(31).

Human rights are often divided between those that protect civil and political rights on the one hand and economic, social, and cultural rights on the other. Civil and political entitlements include the right to life, liberty, and security of person; the prohibition of slavery, torture, and cruel, inhuman, or degrading treatment; freedom from arbitrary interference with privacy, family, or home; and freedom of conscience, religion, expression and association.
Economic, social and cultural rights include the right to social security, education and work, as well as the right to share in scientific advancement and its benefits.

The right to health is rooted in the economic, social and cultural rights found in numerous international documents. Article 25 of the Universal Declaration of Human Rights acknowledges the right to health as a component of "a standard of living adequate for the health and well-being of [a person and that person's] family,... including medical care and necessary social services, and the right to security in the event of...sickness.” The International Covenant on Economic, Social and Cultural Rights (art. 12) adopts a broad concept of health as a human right, declaring "the right of everyone to the highest attainable standard of physical and mental health." States must make efforts to fully realize this right including "the creation of conditions which assure all medical services and medical attention in case of sickness." (art. 12(2)). Regional instruments provide more detailed right to health provisions that specifically outline the States' obligations. The European Social Charter conceives of a right to health that encompasses public health and health care. The descriptive and expansive conception of the right to health advanced by the European Social Charter is mirrored in the Inter-American System's Protocol of San Salvador, which in addition to calling for "enjoyment of the highest level of physical, mental and social wellbeing" includes six specific areas within the right to health, including "satisfaction of the health needs of the highest risk groups...” (Article 10). The African Charter on Human and Peoples' Rights (Article 16) contains “the right to enjoy the best attainable state of physical and mental health" requiring the State to "take necessary measure to protect the health of their people and to ensure that they receive medical attention when they are sick.” 
The right to health is also found in many national constitutions. The Pan American Health Organization examined the right to health in the constitutions of many Latin American countries. Some, including Bolivia, Chile, and Paraguay, enumerate a right to health explicitly in their constitutions(31). Kinney(32) similarly found right to health provisions in numerous national constitutions. The constitutional right to health can be significant in the public health context, forcing governments to pay attention to the needs of the population. For example, the Constitutional Court of South Africa found that the government's refusal to provide antiretroviral medication for pregnant women infected with HIV violated the country's constitution ${ }^{1}$.

The language of human rights is often used for its aspirational, or rhetorical, qualities. When "rights" language is invoked, it is intended to convey the fundamental importance of the claim. It expresses the idea that government should adhere to certain standards, or provide certain services, because it is right and just to do so. Human rights as a symbol commands reverence and respect. Used in this aspirational sense, human rights need not be supported by text, precedent, or reasoning; they are self-evident and government's responsibility simply is to conform.

Although human rights are supported by a body of international law and express an inspiring idea about personal dignity, they are often criticized for imprecision and lack of enforceability. Civil and political rights are perhaps the most precisely defined and carefully studied, but international agencies often fail to rigorously defend these rights in the real world. Economic, social and cultural rights are thought

Minister of Health and Others v. Treatment Action Campaign and Others, CCT 08/02, decided April 4, 2002 http:// www.concourt.gov.za/date2002.html to be vague and unenforceable. For example, the conceptualization of health as a human right, and not simply a moral claim, suggests that states possess binding obligations to respect, defend and promote that entitlement. Considerable disagreement, however, exists as to whether "health" is a meaningful, identifiable, operational and enforceable right, or whether it is merely aspirational or rhetorical.

To achieve the goal of greater clarity and enforceability, the United Nations Committee on Economic, Social, and Cultural Rights issued General Comment No. 14: The Right to the Highest Attainable Standard of Health (2000). General Comment 14 conceives of a right to health that is extensive, fundamental, and "indispensable for the exercise of other human rights." Thus, the right to health encompasses public health and health care, as well as other conditions that are necessary determinants for people to live health lives, including adequate nutrition, housing, uncontaminated drinking water, sanitation, safe workplaces, and a healthy environment. The right to health also contains both "freedoms and entitlements." The freedoms are protections essentially drawn from the context of civil and political rights: the right to have control over one's health and body, sexual and reproductive freedom, and freedom from interference, including the right to be free from torture and from medical treatment or experimentation without consent. The entitlements, by comparison, include an affirmative right to a system of health protection which provides equality of opportunity for people to enjoy the highest attainable level of health. The General Comment considers the right to health in terms of broad norms, state obligations, violations, and implementation standards.

As scholars, practitioners and advocates explore more deeply the meaning of the right to health, it will be helpful to suggest several concrete elements, including the right to: essential 
health services; affordable, quality health care; equality of access to health services; conditions needed to protect and preserve health (e.g., clean water, housing, sanitation); freedom from serious environmental threats; occupational health; minimally adequate education; and enhanced health protection for vulnerable populations.

\section{Tradeoffs Between the Collective Good and Individual Rights}

Public health law, ethics, and human rights often require careful balancing between individual interests in personal (e.g., autonomy, privacy, and liberty) and economic (e.g., contracts and property) freedoms on the one hand and collective interests in health safety and security on the other. Certainly, freedom and security can be mutually reinforcing. Affording individuals their rights can result in greater overall well-being by empowering people to safeguard their own health and safety. For example, if people do not fear loss of privacy or liberty, they are more likely to seek medical and public health services. Coercive powers can literally “drive epidemics underground.”

Sometimes policy makers must make hard tradeoffs between individual and collective interests and, in these circumstances, they need to be guided by ethical values and attentive to legal procedures and norms, as well as human rights. Public health laws and our courts have traditionally balanced the common good with individual civil liberties. As Justice John Marshall Harlan wrote in the seminal United States Supreme Court case of Jacobson v. Massachusetts, 197 U.S. 11 (1905), "the whole people covenants with each citizen, and each citizen with the whole people, that all shall be governed by certain laws for the "common good."' Jacobson was a case that concerned compulsory vaccination, but the difficult tradeoffs between public and private interests can extend to many areas of public health concern ranging from infectious disease control powers (e.g., testing and screening, partner notification, and quarantine) to control of businesses (e.g., inspections and nuisance abatements) and the professions (e.g., licensing).

How should society determine whether to intervene to protect the public's health and safety when doing so will diminish a personal or economic interest? There is no sure way to know when interventions are necessary and appropriate, but here are some of the factors that need to be taken into consideration(26):

Step One: Demonstrate Risk. Risk is a complex idea that involves several dimensions. First, what is the nature of the risk? Risks arise from numerous sources including physical, chemical, organic, environmental and behavioral. Second, what is the duration of the risk? Risks may be imminent, distant, acute or chronic. Third, what is the probability that the risk will actually occur? Risks may be either highly likely or remote. Finally, what is the severity of harm should the risk materialize? Harms can be catastrophic or relatively trivial if they do occur. They may affect individuals or populations, current or future generations, or people or the things that people value (e.g., plants, animals, or the environment).

Step Two: Demonstrate the Intervention's Effectiveness. The intervention should be reasonable likely to reduce the risk. Public health is primarily about prevention so one important measure is whether the intervention is reasonably like to work. This is a "means-ends" inquiry, which seeks to understand if the public health intervention will lead to effective risk reduction.

Step Three: Assess the Economic Cost. The intervention should not only be capable of reducing the risk, but it should do so at a reasonable cost. Policy makers, therefore, should dis- 
cover the costs to the regulatory agency and the subject of the regulation. Wherever possible, policy makers should prefer strategies that are least expensive and most effective. The reason is that government only has limited resources. If it spends money wastefully on an intervention, it will not have those resources available for another, potentially more effective, intervention. Thus, cost-ineffective measures have "lost opportunity" costs.

The criterion to prefer cost-effective measures does not mean that society must wait until there is unassailable scientific evidence before it can intervene. Some advocates have argued for the adoption of a "precautionary principle.” The precautionary principle is not consistently defined but it means that public health authorities may act to prevent future harms to people and the environment even in the absence of conclusive proof that the harm is real or that the intervention will be effective.

Step Four: Assess the Burdens on Human Rights. Sometimes even cost-effective policies should not be undertaken if they disproportionately burden human rights. Policy makers, therefore, should think about the invasiveness of the intervention, the frequency and scope of the infringement, and the duration of the infringement. Human rights do not always trump public health, but they certainly need to be weighed carefully.

Step Five: Assess the Fairness of the Intervention. Policies should be formed and implemented in just ways. Thus, there should be a fair distribution of benefits and burdens. Ethicists examine fairness in a variety of different ways, but they often focus on need and risk. Benefits or public health services should often be distributed based on need. That is, those who have the greatest need should have some claim to the benefit or service. On the other hand, regulatory burdens should often be distributed on the basis of risks posed. That is, those who pose the greatest risks to the public or the environment should bear the costs and burdens of regulation. There are certainly other ways to evaluate the just allocation of benefits and burdens (e.g., principles of the most efficient distribution), but need and risk are two likely criteria.

In summary, a public health intervention can be evaluated using several criteria: (i) the nature, probability and severity of the risk; (ii) the likelihood that it will be effective in meeting its objectives; (iii) the economic costs entailed, including opportunity costs; (iv) the burdens on human rights, and (v) the fairness, including a just allocation of benefits and burdens.

\section{Conclusion}

The field of public health is highly complex. What is the meaning of pivotally important abstract concepts that are common in public health: population, community, risk, harm, and benefit? How should society decide when it is necessary and appropriate to intervene to protect the public's health? Are factors such as risk, effectiveness, cost, burdens and fairness the best ways to evaluate public health interventions? How does the population perspective differ from the individual perspective? To what extent should social justice be an animating value in public health? Scholars and practitioners use various forms of reasoning in analyzing these problems, notably ethics, law, and human rights. Each form of reasoning has its own benefits and disadvantages. While each form of reasoning is distinct, all the forms overlap in important ways. One thing is certainly clear, there are no "correct" answers in public health. However, careful examination of principles and values taken from each of these fields can clarify thinking and, ultimately, lead to more effective and just policies and practices in public health. 


\section{References}

1. Turnock BJ. Public Health: What it is and how it works. Gaithersburg, MD: Aspen Publishers; 2001.

2. Novick LF, Mays GP, eds. Public health administration: principles for population-based management. Gaithersburg, MD: Aspen Publishers; 2001.

3. Beaglehole R, Bonita R. Public Health at the Crossroads: Achievements and prospects. Cambridge, UK; New York, NY, USA: Cambridge University Press; 1997.

4. Fielding JE. Public Health in the Twentieth Century: Advances and Challenges. Annual Review of Public Health 1999; 20: xiii-xxx.

5. Preamble to the Constitution of the World Health Organization as adopted by the International Health Conference, New York, 19-22 June, 1946; signed on 22 July 1946 by the representatives of 61 States (Official Records of the World Health Organization, no. 2, p. 100) and entered into force on 7 April 1948.

6. Winslow CA. The Untilled Fields of Public Health. Science 1920; 20-30.

7. Institute of Medicine. The Future of Public Health. Washington, DC: National Academy Press; 1988.

8. McKinlay JB, McKinlay SM. The Questionable Contribution of Medical Measures to the Decline of Mortality in the United States in the Twentieth Century. Milbank Quarterly 1977; 55: 405-29.

9. Gostin LO. Public Health Law: Power, Duty, Restraint. Berkeley and New York: University of California Press and Milbank Memorial Fund; 2000.

10. Gostin LO. Public Health, Ethics, and Human Rights: A Tribute to the Late Jonathan Mann. Journal of Law, Medicine, and Ethics 2001; 29: 121-30.

11. Marmot M, Wilkinson RG eds. Social determinants of health. Oxford, UK; New York, NY, USA: Oxford University Press, 1999.

12. Syme SL. Social and Economic Disparities in Health: Thoughts about Intervention. Milbank Quarterly 1998; 76: 493-505.

13. Cattell V. Poor People, Poor Places, and Poor Health: The Mediating Role of Social Networks and Social Capital. Social Science and Medicine 2001; 52: 1501-16.

14. Smedley BD, Stith AY, Nelson AR, eds. Unequal treatment: confronting racial and ethnic disparities in health care. Committee on Understanding and Eliminating Racial and Ethnic Disparities in Health Care, Board on Health Sciences Policy, Institute of Medicine. Washington DC: National Academies Press; 2003.

15. Hancock T. Healthy Communities Must Also Be Sustainable Communities. Public Health Reports 2000; 115:151-6.

16. Maantay J. Zoning, Equity, and Public Health. American Journal of Public Health 2001; 91: 1033-41.

17. Breakey WR. It's Time for the Public Health Community to Declare War on Homelessness. American Journal of Public Health 1997; 87: 153-5.

18. Berkman LF, Kawachi I, eds. Social Epidemiology. Oxford, UK; New York, NY, USA: Oxford University Press; 2000. 
Public Health Ethics: Tradition, Profession, and Values - L. O. Gostin

19. Daniels N, Kennedy B, Kawachi I. Justice is Good for Our Health. Boston Review 2000; February/ March: 6-15.

20. Kass NE. An Ethics Framework for Public Health. American Journal of Public Health 2001; 91:1776-82.

21. Beauchamp DE, Steinbock B, eds. New Ethics for the Public's Health. New York: Oxford University Press; 1999.

22. Callahan D, Jennings B. Ethics and Public Health: Forging a Strong Relationship. American Journal of Public Health 2002; 92:169-76.

23. Thomas JC, Sage M, Dillenberg J, Guillory VJ. A Code of Ethics for Public Health. American Journal of Public Health 2002; 92:1057-9.

24. Childress JF, Faden RR, Gaare RD, Gostin LO, et al. Public Health Ethics: Mapping the Terrain. The Journal of Law, Medicine, \& Ethics 2002; 30(2): 170-81.

25. Coughlin S, Katz WH, Mattison DR. Ethics Instruction at Schools of Public Health in the United States. American Journal of Public Health 2000; 90: 768-70.

26. Gostin LO, ed. Public Health Law and Ethics: A Reader. Berkeley and New York: University of California Press and Milbank Memorial Fund; 2002.

27. World Health Organization. Framework Convention on Tobacco Control. [Website] Available in http:/ /www.who.int/tobacco/fctc/en/ Visited August 25, 2003.

28. Perdue W, Stone L, Gostin LO. The Built Environment and Its Relationship to the Public's Health: The Legal Framework. American Journal of Public Health 2003; 93:9.

29. Gostin LO. The AIDS Pandemic: Complacency, Injustice, and Unfulfilled Expectations. Raleigh: University of North Carolina Press; 2004.

30. Mann JM, Gostin LO, Gruskin S, et al. Health and Human Rights. Journal of Health and Human Rights 1994; 1: 6-23.

31. Fuenzalida-Puelma HL, Connor SS, eds. The Right to Health in the Americas: A Comparative Constitutional Study. Washington DC: Pan American Health Organization; 1989.

32. Kinney, ED. The International Human Right to Health: What Does This Mean for Our Nation and World? Indiana Law Review 2001; 34: 1457-75. 